\title{
Surgical preconditioning and completion of total cavopulmonary connection by interventional cardiac catheterisation: a new concept
}

\author{
Gerd Hausdorf, Martin Schneider, Wolfgang Konertz
}

\begin{abstract}
A new, staged procedure for univentricular repair of "high risk" patients using a combined surgical transcatheter technique is reported. As first step a surgical hemifontan procedure was performed and a multifenestrated patch inserted into the right atrium. For later transcatheter completion of univentricular repair, a subtotal banding just above the cavoatrial junction was performed. Two months later transcatheter completion was performed by balloon dilatation of the banded cavo-atrial junction and additionally either by inserting a covered stent as intracardiac conduit between the superior and inferior vena cava or by inserting a (non-covered) stent into the cavo-atrial junction and occluding the fenestrations in the right atrial patch using RashkindPDA occluders. This new technique was successfully applied without mortality in eight patients with a preoperative mean pulmonary pressure of 18 to $23 \mathrm{~mm} \mathrm{Hg}$. No complications typical for Fontan-like corrections occurred within the follow up period of 4 to 14 months.
\end{abstract}

(Heart 1996;75:403-409)

Keywords: total cavopulmonary connection; univentricular heart; combined surgical-transcatheter repair; Fontan operation

Univentricular repair (Fontan procedure, total cavopulmonary connection) is an established treatment for patients with only one functioning ventricle. However, the hazard of this procedure is still high, depending on ventricular function, the size of the pulmonary arteries, and pulmonary resistance. ${ }^{12}$ The risk of postsurgical death and morbidity has been reduced by fenestrating the baffle between the systemic and pulmonary venous atria, resulting in lower pressures in the superior and inferior vena cava as well as in the right atrium. ${ }^{3-5}$ For "high-risk" patients, a staged univentricular repair has been proposed ${ }_{2}^{5-8}$ which consists of a hemifontan procedure as the first stage, during which a surgical anastomosis between the superior vena cava and the (right) pulmonary artery is created. As the second stage, total cavopulmonary connection and thereby completion of univentricular repair is achieved by use of an intracardiac or extracardiac conduit between the inferior vena cava and the pulmonary artery. To reduce the number of operations required to achieve staged univentricular repair and to broaden this therapeutic approach, we combined surgical with interventional techniques to perform staged, total cavopulmonary connection. As the first stage, a modified surgical hemifontan procedure is performed, which prepares the patient for subsequent transcatheter completion of univentricular repair. Completion of total cavopulmonary connection is achieved by transcatheter techniques, eliminating the need for repeated cardiac surgery.

\section{Methods}

PATIENTS

In eight patients (age 2-13 years) with increased risk for univentricular repair (mean pulmonary pressure $18 \mathrm{~mm} \mathrm{Hg}$ or higher, distortion or stenosis of the pulmonary arteries) a two stage univentricular repair combining surgical preconditioning and interventional completion was attempted. ${ }^{12}$ The individual patient data are summarised in table 1 .

\section{PROCEDURE}

First stage

As the first stage a modified hemifontan operation was performed. The superior vena cava was surgically anastomosed with the right pulmonary artery, while the main pulmonary artery - and when required an aortopulmonary shunt-were ligated. A subtotal banding of the communication between the superior vena cava and the right atrium was performed over a 16 gauge catheter using $6-0$ prolene, so that a minimal communication between the right atrium and the pulmonary artery was maintained for later transcatheter completion. 6-0 Prolene was chosen to perform the banding, as this is easily ruptured during balloon dilatation. Additionally a multiperforated Gore-tex baffle with three to seven perforations $5 \mathrm{~mm}$ in diameter was inserted laterally into the right atrium.

\section{Second stage}

Two months later the second stage or "trans-

The Charité, Paediatric Cardiology, G Hausdorf

The Charité, Department of
Cardiac Surgery W Konertz

Correspondence to: Charité, HumboldtUniversität zu Berlin, 10 October 1995
} 
Table 1 Preoperative data

\begin{tabular}{|c|c|c|c|c|c|}
\hline Patient & $\begin{array}{l}\text { Age } \\
\text { (years) }\end{array}$ & $\begin{array}{l}\text { Weight } \\
(\mathrm{kg})\end{array}$ & Diagnosis & $\begin{array}{l}p P A \\
(m m \mathrm{Hg})\end{array}$ & $\begin{array}{l}\text { Pulmonary } \\
\text { vessels }\end{array}$ \\
\hline 1 & 6 & 16 & $\begin{array}{l}\text { DILV, } \\
\text { 1-MGA, PS }\end{array}$ & 23 & - \\
\hline 2 & 5 & 13 & $\begin{array}{l}\text { Tricuspid atresia, } \\
\text { PA banding }\end{array}$ & 20 & - \\
\hline 3 & 6 & 17 & $\begin{array}{l}\text { Tricuspid atresia } \\
\text { d-MGA, PS, } \\
\text { Waterston shunt }\end{array}$ & 19 & $\begin{array}{l}\text { Distortion } \\
\text { of RPA } \\
\text { after } \\
\text { Waterston } \\
\text { shunt }\end{array}$ \\
\hline 4 & 7 & 17 & $\begin{array}{l}\text { Tricuspit atresia } \\
\text { PS, } \\
\text { Waterston shunt }\end{array}$ & 18 & $\begin{array}{l}\text { Distortion } \\
\text { of RPA } \\
\text { after } \\
\text { Waterston } \\
\text { shunt }\end{array}$ \\
\hline 5 & 3 & 10 & $\begin{array}{l}\text { Tricuspid atresia } \\
\text { PA banding }\end{array}$ & 22 & $\begin{array}{l}\text { Distortion } \\
\text { after } \\
\text { PA-banding }\end{array}$ \\
\hline 6 & 13 & 33 & $\begin{array}{l}\text { Criss cross } \\
\text { 1-MGA, PS, VSD, } \\
\text { hypoplastic RV, } \\
\text { BT shunt }\end{array}$ & 20 & $\begin{array}{l}\mathrm{RPA} \\
\text { stenosis } \\
\text { Ao-PA } \\
\text { collaterals }\end{array}$ \\
\hline 7 & 2 & 8 & $\begin{array}{l}\text { Hypoplastic TV, } \\
\text { hypoplastic RV, } \\
\text { pulmonary atresia, VSD, } \\
\text { BT shunt }\end{array}$ & 18 & $\begin{array}{l}\text { Hypoplastic } \\
\text { PA vessels }\end{array}$ \\
\hline 8 & 2 & 12 & $\begin{array}{l}\text { d-transposition, } \\
\text { swiss cheese VSD } \\
\text { valvar and subvalvar } \\
\text { PS }\end{array}$ & 18 & MAPCAs \\
\hline
\end{tabular}

Age, age at surgical preconditioning; pPA, mean pulmonary pressure; pulmonary vessels, state of the pulmonary vessels; MGA, malposition of the great arteries; DILV, double inlet left ventricle; criss cross, criss cross heart; PS, pulmonary stenosis; RPA, right pulmonary artery; PA banding, banding of the main pulmonary artery; hypoplastic TV, hypoplastic and stenotic tricuspid valve; RV, right ventricle; BT shunt, Blalock-Taussig shunt; MAPCA, major aorto-pulmonary collateral arteries.

catheter completion" of univentricular repair was attempted. Diagnostic cardiac catheterisation was performed from the femoral vein. The pressures in the right atrium and in the superior vena cava were measured. In the first two patients only, general anaesthesia was performed and in addition to the access from the femoral vein a $5 \mathrm{~F}$ sheath was inserted into the right jugular vein. A guidewire railway $(0.035$ in, TSF guidewire, $260 \mathrm{~cm}$, Cook) was established from the femoral vein to the jugular vein in these patients, to allow occlusion of the superior vena cava-right atrial junction with a balloon catheter in case of acute cyanosis during the procedure due to preferential flow from the superior vena cava to the right atrium. This was not done in the subsequent patients, in whom sedatation was achieved using diazepam and ketamine.

A right atrial angiogram was performed to delineate the perforations within the right atrial baffle using a $5 \mathrm{~F}$ pigtail catheter (Cordis). The pigtail catheter was exchanged against a $5 \mathrm{~F}$ right Judgkins catheter (Cordis) and the banding site crossed with a 0.035 in guidewire (THSF, $260 \mathrm{~cm}$, Cook). The $5 \mathrm{~F}$ right Judgkins catheter was exchanged for a $5 \mathrm{~F}$ pigtail catheter (Cordis) and an angiogram into the superior vena cava was performed to delineate the anastomoses between superior vena cava and the right pulmonary artery. To delineate the banding site the catheter was positioned with some of the side holes within the pulmonary artery and some within the right atrium, and an angiogram performed. When the banding site could not be crossed with a diagnostic catheter, a 0.018 in guidewire was advanced through the banding site and balloon angioplasty performed using a PTCA catheter (Olimpix, balloon length 2 $\mathrm{cm}$, inflated balloon diameter at nominal pres- sure $3 \mathrm{~mm}$; Cordis) which was inflated to a pressure of 6 atmospheres.

The technique to be used for transcatheter completion of univentricular repair was chosen according to the right atrial angiogram which showed the perforations within the right atrial baffle. When the perforations in the baffle seemed to be suitable for transcatheter closure using "large" (17 mm diameter) RashkindPDA occluders (Bard), the banding site was enlarged by balloon dilatation and the subsequent stenting using Palmaz iliac stents, followed by occlusion of the fenestrations within the baffle using Rashkind-PDA occluders (technique 1, see below). When the perforations seemed to be unsuitable for occlusion with "large" (17 mm diameter) RashkindPDA occluders, an individually designed covered wallstent was manufactured (Medinvent) and implanted as "intracardiac conduit" between the banding site and the inferior vena cava after balloon dilation of the banding site (technique 2 , see below).

Technique 1-As initial step dilation of the banding site was performed, using a balloon catheter (Opta, Cordis) with a nominal balloon diameter of $6 \mathrm{~mm}$. The balloon catheter was introduced over a 0.035 in guidewire (THSF, $260 \mathrm{~cm}$, Cook) and inflated to an inflation pressure of 2 to $4 \mathrm{~atm}$. The balloon catheter was exchanged for an $8 \mathrm{~F}$ long sheath (Bard), which had been individually preshaped over hot vapour and was advanced over the 0.035 in guidewire through the banding site. A Palmaz iliac stent $(12 \mathrm{~mm}$ long, Johnson and Johnson Interventional Systems) was manually mounted on a balloon catheter (Opta, balloon length $2 \mathrm{~cm}$, balloon diameter at nominal pressure $8 \mathrm{~mm}$, Cordis) and advanced over the 0.035 in guidewire through the $8 \mathrm{~F}$ long sheath until the stent was positioned within the banding site. The long sheath was retrieved and the adequate position of the stent controlled by an angiogram from a venous line in the right cubital vein. Implantation of the stent was performed by inflating the balloon to a pressure of $6 \mathrm{~atm}$. Further expansion of the stent was achieved by inflating the balloon to an inflation pressure of up to $12 \mathrm{~atm}$ (diameter $9.2 \mathrm{~mm}$ ) and then by use of a $10 \mathrm{~mm}$ balloon (Opta, $6 \mathrm{~atm}$ inflation pressure, Cordis). During this procedure continuous monitoring of the transcutaneous oxygen saturation was performed, to be aware of a significant fall of the arterial oxygen saturation due to an increased blood flow from the superior vena cava to the systemic circulation.

Following balloon dilatation of the superior vena cava-right atrial junction, transcatheter occlusion of the perforations in the baffle was performed. For this purpose the preshaped $8 \mathrm{~F}$ long sheath was positioned with its tip in the distal inferior vena cava and the perforations within the baffle were crossed with a $5 \mathrm{~F}$ right Judgkins catheter or Cobra catheter (Cordis). After crossing the baffle a 0.035 in guidewire $(260 \mathrm{~cm}$, THSF, Cook) was advanced into a pulmonary vein, the $5 \mathrm{~F}$ catheter exchanged against the $8 \mathrm{~F}$ dilator and the $8 \mathrm{~F}$ long sheath advanced into the left atrium. Using the "front 
loading technique"9 a $17 \mathrm{~mm}$ Rashkind-PDA occluder (Bard) was advanced through this $8 \mathrm{~F}$ long sheath. When the distal legs of the occluder opened within the left atrium the long sheath was retracted, so that the proximal umbrella could open on the right side of the baffle. After occlusion of the perforations in the baffle, further balloon dilatation of the Palmaz stent was performed to a diameter of 14 to 16 $\mathrm{mm}$.

Technique 2-When the perforations within the baffle were unsuitable for occlusion using Rashkind-PDA occluders because they were located close to the atrial wall or because additional leaks at the suture line of the intracardiac baffle were apparent, a covered wallstent was implanted as an intracardiac conduit. To determine the required length and diameter of the covered wallstent, as well as the length of the covered and uncovered part of the stent, angiograms of the superior vena cava, the right atrium, the inferior vena cava, and the hepatic veins were performed as described above. According to these measurements, a covered wallstent was individually manufactured by Medinvent (Schneider, Switzerland) as "intracardiac conduit" between the superior and inferior vena cava. Implantation of the covered wallstents was performed after informed consent and approval by the local ethics committee had been obtained. The banding site was predilated to a diameter of $16 \mathrm{~mm}$ as described above. The covered wallstent was then inserted from the femoral vein over a 0.035 in guidewire transcutaneously. Predilatation of the femoral vein was performed to insert the $18 \mathrm{~F}$ delivery instrument for the covered wallstent.

\section{Anticoagulation}

During the procedure $100 \mathrm{U} / \mathrm{kg}$ heparin were given intravenously, and the antithrombin III blood level was kept above $90 \%$. After the procedure heparin was continued and dicoumarol was started. The latter was given for four months. Heparin was given as a continuous infusion. During the first 24 hours $600 \mathrm{IU} / \mathrm{kg}$ were given, followed by $400 \mathrm{IU} / \mathrm{kg} / \mathrm{d}$ until the international normalised ratio (INR) was $1 \cdot 8$. Additionally 3 to $5 \mathrm{mg} / \mathrm{kg}$ aspirin were given orally.

\section{Results}

SURGICAL PRECONDITIONING

Before the first (surgical) stage of the staged univentricular repair was performed, the mean pulmonary pressure ranged from 18 to $23 \mathrm{~mm}$ $\mathrm{Hg}$ and the arterial oxygen saturation from $71 \%$ to $88 \%$ (table 2 ). In two of eight patients we ligated a Waterston shunt and in two others a modified Blalock-Taussig shunt. The main pulmonary artery was dissected and occluded in four patients. Surgical reconstruction of the pulmonary branches was performed in four of eight patients using autologous pericardium. While surgical preconditioning required a cross clamp time of $79 \mathrm{~min}$ in the first patient, this was reduced in the consecutive patients to 19 min (mean cross clamp time $46.7 \mathrm{~min}$ ). No hypothermia was used during surgery, and the patients were extubated 3.5 to 12 hours postoperatively. The arterial oxygen saturation ranged from $70 \%$ to $81 \%$ postoperatively and total chest tube drainage from 11 to $22 \mathrm{ml} / \mathrm{kg}$; none of the patients required chest tube drainage for more than three days or developed pleural effusions or other complications typical for Fontan-type corrections. For anticoagulation, aspirin 2 to 3 $\mathrm{mg} / \mathrm{kg}$ was given orally until interventional completion was performed.

\section{TRANSCATHETER COMPLETION}

Transcatheter completion of univentricular repair was successfully performed in all patients 6 to 10 weeks after the first stage. Only the first two procedures were performed during general anaesthesia. In these two patients both the right femoral vein and the right jugular vein were punctured, and a guidewire railway from the femoral vein and to the jugular vein was established. Because the interventional completion turned out to be rather uncomplicated, without deleterious decrease in the arterial oxygen saturation, general anaesthesia and puncture of the right jugular vein were abandoned in the subsequent patients. The communication between the superior vena cava and the right atrium had a minimum diameter of 0.2 to $0.5 \mathrm{~mm}$. In two patients predilatation using a PTCA catheter (Olimpix, balloon length $2 \mathrm{~cm}$, inflated balloon diameter at nominal pressure $3 \mathrm{~mm}$; Cordis) which was inflated to a pressure of $6 \mathrm{~atm}$ was necessary to be able to cross the banding site with a diagnostic catheter. After diagnostic catheterisation, incremental balloon dilatation of the cavo-atrial junction was performed to a diameter of $10 \mathrm{~mm}$. The waist in the balloon disappeared at an inflation

Table 2 Haemodynamic data. Haemodynamic data before and after surgical preconditioning as well as before and immediately after interventional completion of total cavopulmonary connection

\begin{tabular}{|c|c|c|c|c|c|c|c|c|c|c|c|c|}
\hline \multirow[b]{3}{*}{ Patient } & \multicolumn{6}{|c|}{ Surgical preconditioning } & \multicolumn{6}{|c|}{ Intervention completion } \\
\hline & \multicolumn{3}{|c|}{ Before } & \multicolumn{3}{|l|}{ After } & \multicolumn{3}{|c|}{ Before } & \multicolumn{3}{|l|}{ After } \\
\hline & $p P A$ & $p R A$ & Sat & $p P A$ & $p R A$ & Sat & $p P A$ & $p R A$ & Sat & $p P A$ & $p R A$ & Sat \\
\hline $\begin{array}{l}1 \\
2 \\
3 \\
4 \\
5 \\
6 \\
7 \\
8\end{array}$ & $\begin{array}{l}23 \\
20 \\
19 \\
18 \\
22 \\
20 \\
18 \\
18\end{array}$ & $\begin{array}{r}6 \\
9 \\
9 \\
12 \\
12 \\
9 \\
9 \\
9\end{array}$ & $\begin{array}{l}88 \\
86 \\
88 \\
80 \\
80 \\
83 \\
79 \\
71\end{array}$ & $\begin{array}{r}8 \\
9 \\
8 \\
9 \\
7 \\
8 \\
10 \\
8\end{array}$ & $\begin{array}{r}9 \\
6 \\
7 \\
9 \\
7 \\
9 \\
10 \\
8\end{array}$ & $\begin{array}{l}78 \\
79 \\
75 \\
76 \\
79 \\
79 \\
87 \\
83\end{array}$ & $\begin{array}{l}9 \\
7 \\
7 \\
8 \\
6 \\
7 \\
7 \\
7\end{array}$ & $\begin{array}{l}9 \\
7 \\
6 \\
7 \\
7 \\
8 \\
7 \\
7\end{array}$ & $\begin{array}{l}71 \\
73 \\
72 \\
73 \\
74 \\
76 \\
81 \\
79\end{array}$ & $\begin{array}{l}8 \\
8 \\
7 \\
7 \\
7 \\
6 \\
6 \\
7\end{array}$ & $\begin{array}{r}10 \\
8 \\
7 \\
9 \\
8 \\
8 \\
7 \\
7\end{array}$ & $\begin{array}{l}96 \\
91 \\
97 \\
94 \\
96 \\
88 \\
92 \\
94\end{array}$ \\
\hline
\end{tabular}

pPA, mean pulmonary arterial pressure $(\mathrm{mm} \mathrm{Hg})$; pRA, mean right atrial pressure ( $\mathrm{mm} \mathrm{Hg}$ ); Sat, arterial oxygen saturation (\%). 

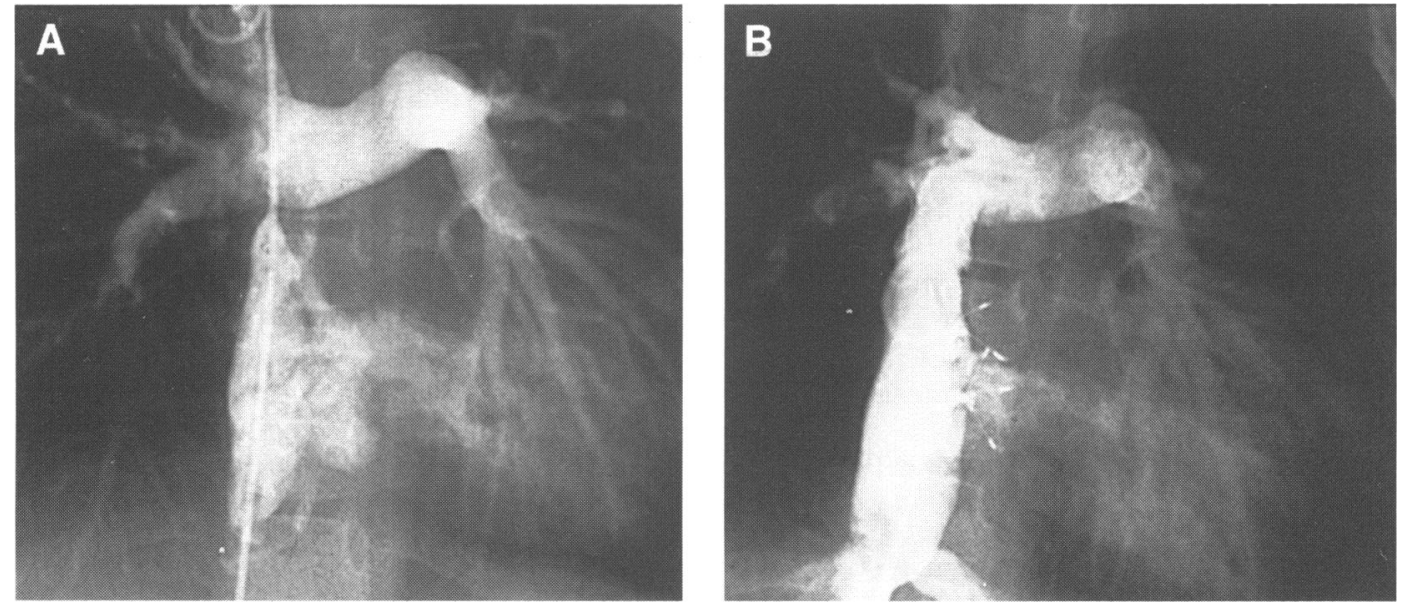

Figure 1 Angiography before transcatheter Fontan completion in a 2 year old patient with tricuspid atresia $(A)$. The subtotally banded cavo-atrial junction has been passed by a catheter delineating both the pulmonary artery anastomosed to the superior ven cava and the right atrium with the multiperforated baffle. Transcatheter Fontan completion $(B)$ was achieved by implanting a Palmaz stent (fohnson and fohnson) into the cavo-atrial junction and occluding the fenestrations in the right atrial baffle with two $17 \mathrm{~mm} P D A$ occluders (Bard). A small residual right to left shunt through the fenestrated baffle is still visible immediately after the procedure.

pressure of 3 to 4 atm during angioplasty of the iatrogenic stricture of the cavo-atrial junction. Surprisingly, the arterial oxygen saturation did not decrease significantly during this part of the procedure, although the fenestrations within the baffle were still patent.

In six patients a Palmaz stent $(12 \mathrm{~mm}$ iliac stent, Johnson and Johnson interventional) was implanted into the cavo-atrial junction and dilated up to a diameter of $13-16 \mathrm{~mm}$. The Palmaz stents shortened from a length of $12 \mathrm{~mm}$ to $10.6 \mathrm{~mm}$ when expanded to a diameter of $10 \mathrm{~mm}$, to a length of $9.8 \mathrm{~mm}$ when expanded to a diameter of $12 \mathrm{~mm}$, to a length of $8.4 \mathrm{~mm}$ when expanded to a diameter of 14 $\mathrm{mm}$, and to a length of $7.4 \mathrm{~mm}$ when expanded to a diameter of $16 \mathrm{~mm}$. Thereafter

Figure 2 Angiography after surgical

preconditioning is shown in this 3 year old patient with tricuspid atresia $(A)$; transcatheter completion of univentricular repair was achieved by implanting $a$ covered wallstent (Medinvent) as intracardiac conduit between the superior and inferior vena cava $(B, 4$ months after implantation of the covered wallstent); 12 months after the procedure $(C)$ further expansion of the stent has occurred, while the tissue within the covered wallstent has regressed.
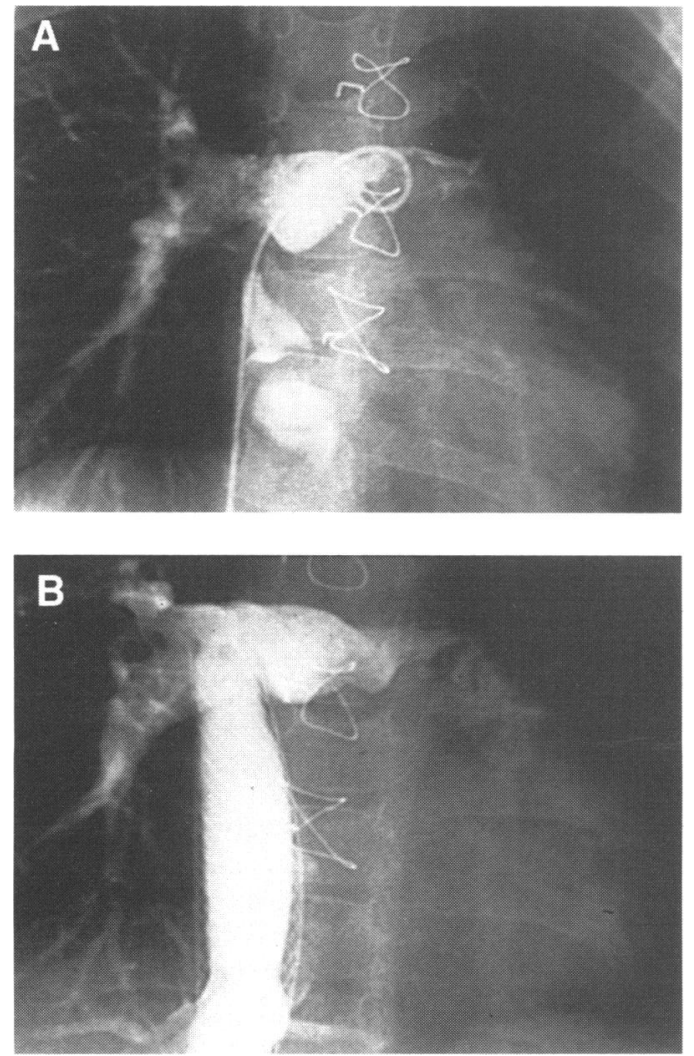

the multiperforated patch was occluded using two to five "large" (17 mm diameter) Rashkind-PDA occluders (Bard) through the $8 \mathrm{~F}$ long sheath, which had been inserted for stent implantation (fig 1).

In two patients, leaks at the suture line of the intracardiac baffle were apparent in addition to the fenestrations within the baffle. Balloon sizing of these defects (6F Berman end open catheter with a $16 \mathrm{~mm}$ latex balloon, special request, Arrows) revealed a defect diameter of $10 \mathrm{~mm}$ and $12 \mathrm{~mm}$, so that these leaks were not suitable for closure using Rashkind-PDA occluders. In these two patients a covered wallstent (Medinvent, Switzerland) was implanted after predilating the communication between superior vena cava and right atrium sequentially to a diameter of $14 \mathrm{~mm}$ and $16 \mathrm{~mm}$. The covered wallstents had an expanded diameter of $20 \mathrm{~mm}$ and length of $65 \mathrm{~mm}$. Both ends of these covered wallstents were left uncovered, distally $1 \mathrm{~cm}$, proximally $1.5 \mathrm{~cm}$. Implantation was performed transcutaneously, from the femoral vein using an $18 \mathrm{~F}$ delivery system. The length of the stent in the delivery system (before expansion) was $10 \mathrm{~cm}$. The covered wallstents were implanted between the superior vena

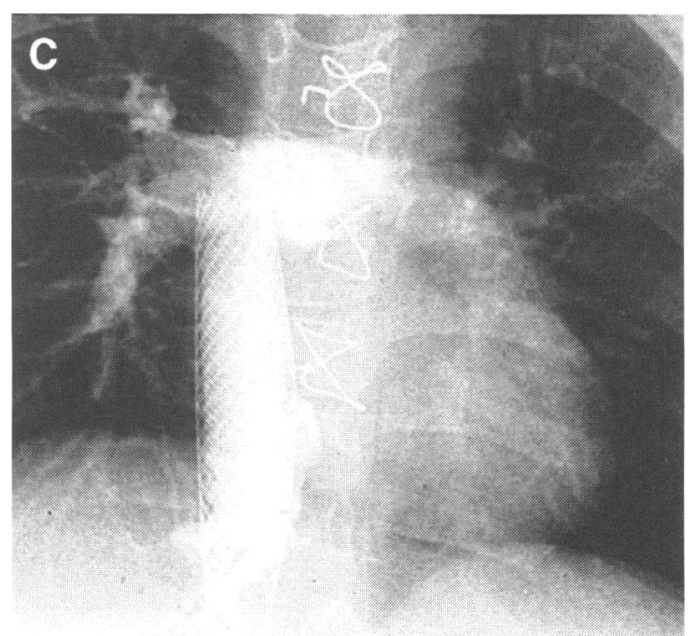


Table 3 Haemodynamic data at follow up cardiac catheterisation

\begin{tabular}{|c|c|c|c|c|c|}
\hline \multirow[b]{2}{*}{ Patient } & \multirow{2}{*}{$\begin{array}{l}\text { Total follow up } \\
\text { period (months) }\end{array}$} & \multirow{2}{*}{$\begin{array}{l}\text { Time of } \\
\text { recatheterisation } \\
\text { (months) }\end{array}$} & \multicolumn{3}{|c|}{$\begin{array}{l}\text { Haemodynamic data } \\
\text { at recatheterisation }\end{array}$} \\
\hline & & & $p P A(m m H g)$ & $p R A(m m H g)$ & Sat (\%) \\
\hline $\begin{array}{l}1 \\
2 \\
3 \\
4 \\
5 \\
6 \\
7 \\
8\end{array}$ & $\begin{array}{r}14 \\
13 \\
12 \\
8 \\
8 \\
6 \\
6 \\
3\end{array}$ & $\begin{array}{l}4 \\
4 \\
4 \\
4 \\
6 \\
4 \\
4 \\
-\end{array}$ & $\begin{array}{l}8 \\
7 \\
6 \\
7 \\
6 \\
6 \\
7 \\
-\end{array}$ & $\begin{array}{l}8 \\
6 \\
7 \\
8 \\
7 \\
6 \\
7 \\
-\end{array}$ & $\begin{array}{l}97 \\
97 \\
96 \\
96 \\
96 \\
94 \\
95 \\
94^{\star}\end{array}$ \\
\hline
\end{tabular}

*No follow up cardiac catheterisation performed, the oxygen saturation was measured transcutaneously 4 weeks and 2 months after completion.

Time interval, time between interventional completion and follow up investigation; pPA, mean pulmonary arterial pressure; pRA, mean right atrial pressure; Sat, arterial oxygen saturation.

cava and the inferior vena cava as "intracardiac conduit" (fig 2). Care was taken not to occlude hepatic veins by the covered part of the covered wallstent, uncompromised drainage of the hepatic veins was confirmed by selective angiograms and upper abdominal sonography.

\section{FOLLOW UP DATA}

The arterial oxygen saturation increased in the total group of patients from $71 \%$ to $83 \%$ preinterventionally and to $92 \%$ to $97 \%$ postinterventionally (measured on the third day after completing staged univentricular repair); the mean right atrial pressure increased from 6 to 9 $\mathrm{mm} \mathrm{Hg}$ preinterventionally (mean $7.4 \mathrm{~mm}$ $\mathrm{Hg}$ ) to 7 to $9 \mathrm{~mm} \mathrm{Hg}$ (mean $7.6 \mathrm{~mm} \mathrm{Hg}$ ) postinterventionally (table 3 ). The screening times ranged from 12-28 min and the procedural times from 52-137 min. No significant complications occurred after the procedure or during the follow up period of 4 to 14 months, the quality of life improved dramatically in all patients. In particular no complications typical for Fontan-type corrections such as pleural effusions, ascites, renal failure, hepatic failure, or protein losing enteropathy were observed after the procedure or during the follow up period of 4 to 14 months. Echocardiography revealed no residual leak in the baffle, although the transcutaneous oxygen saturation ranged from $88 \%$ to $97 \%$, indicating residual right to left shunting in at least some of the patients (table 3). Holter monitoring showed normal sinus rhythm, with no dysrhythmias or sinus node dysfunction. In both patients who received a covered wallstent, recatheterisation was performed four months after Fontan completion. No residual leaks were found, and in both patients tissue appeared within the covered wallstent; in one patient this tissue had a thickness of less than $0.3 \mathrm{~mm}$. This "tissue" could reflect either intimal proliferation or thrombotic deposits within the stent. In the other patient the tissue appearing within the covered wallstent was more prominent, with a thickness of $0.4 \mathrm{~mm}$ to $2.9 \mathrm{~mm} 4$ months after the implantation (fig 2B); surprisingly this tissue seemed to have regressed at recatheterisation 12 months after the implantation (fig 2C). In this patient an antithrombin III deficiency was present. At the time of writing the patient was well and had been living a normal life for 10 months.

\section{Discussion}

Although the Fontan principle is a palliative procedure, its application in patients with univentricular circulation is currently being broadened. .-8 $^{1011}$ Various types of univentricular repair including hemifontan-type or Glenntype operation, fenestrated Fontan-type operation, and non-fenestrated Fontan-type operation are currently performed..$^{10}$ Decompressing the right atrium by use of a fenestrated baffle and subsequent transcatheter closure of the fenestration has been of particular importance in reducing the mortality early after a Fontan procedure. ${ }^{346}$ Fenestrating the baffle also seems to be effective in overcoming transient problems of the early postoperative period resulting from pulmonary dysfunction, increased pulmonary resistance, transient ventricular dysfunction, and the haemodynamic changes themselves. ${ }^{3}$ The incidence of serious effusions is significantly reduced. ${ }^{10}$ Particularly in high risk patients, the incidence of postsurgical mortality and morbidity, including renal failure, hepatic dysfunction, severe effusions, and protein losing enteropathy, has been reduced significantly using a staged univentricular repair..$^{1010-14}$ The major advantage of a bidirectional Glenn operation or hemifontan operation is relief of the systemic ventricle from volume overload so that it is allowed to remodel before univentricular repair is completed. ${ }^{15} 16$ Additionally the sudden conversion to a Fontan-type circulation is avoided. Jacobs and Norwood ${ }^{7}$ reported a reduction of overall mortality (within 30 days of operation) from $16 \%$ in 223 patients who underwent a modified Fontan procedure without prior hemifontan to $8 \%$ in 200 patients who underwent a hemifontan procedure before univentricular repair was completed. This mortality was further reduced to $4.5 \%$ in 112 patients by creating one or more fenestrations in the baffle or by excluding one or more hepatic veins from the systemic venous pathway. ${ }^{7}$ However, if univentricular repair is performed in two stages an additional operation becomes necessary. To combine the advantages of baffle fenestration and of a staged univentricular repair, but eliminating the need for repeated surgery, we developed our new concept of staged, surgical-transcatheter univentricular repair, which combines surgical "preconditioning" and transcatheter "completion" of univentricular repair. Despite our limited experience, 
these data show that this approach was successfully applied in high risk patients and could become a promising alternative to the conventional staged correction. Although the youngest patient in this series was 2 years old and weighed $8 \mathrm{~kg}$, our first technique (implanting a Palmaz stent into the cavo-arterial junction and device closure of the fenestrations) seems to be applicable also in the first year of life, so that early univentricular repair seems possible using this approach. ${ }^{17}$

As the first step in this new concept, a hemifontan-type circulation is established surgically, concomitantly preconditioning the patient for later transcatheter Fontan completion. This is achieved by maintaining a minimal communication between the superior vena cava and the right atrium and by inserting a multiperforated baffle laterally into the right sided atrium. The main goal of unloading the systemic ventricle is achieved by this first (surgical) stage, the systemic ventricle being allowed to remodel before transcatheter completion of the univentricular repair is performed. In our experience the postsurgical course after the first (surgical) stage was as smooth as after bidirectional Glenn operation, with none of the complications that are typical of Fontan-like procedures.

The major advantage of this new concept is that repeated surgery can be reduced; additionally myocardial ischaemia does not occur during completion of univentricular repair. Although increased cyanosis during the interventional procedure was a matter of concern, no increase in right to left shunting occurred after balloon dilatation of the cavo-atrial junction when the fenestrations in the baffle were still patent. As the conversion from a hemiFontan to a Fontan-type circulation proved to be smooth, only the first two procedures were performed under general anaesthesia, while the subsequent procedures were performed under sedation. Complications typical for Fontan-type corrections were not observed in any of our patients after surgical preconditioning or after transcatheter completion. The mean right atrial pressure increased from $7 \cdot 4$ $\mathrm{mm} \mathrm{Hg}$ to $7.6 \mathrm{~mm} \mathrm{Hg}$ during transcatheter completion. The smooth and uneventful clinical course during and after both stages suggests that the risks inherent to the surgical establishment of a Fontan-type circulation can be further reduced by this approach.

Despite these promising experiences, some potential disadvantages should be mentioned. For the surgical preconditioning, extracorporeal circulation is necessary to insert the multiperforated baffle. However, the cross clamp time was reduced continuously from $79 \mathrm{~min}$ utes in the first patient to 19 minutes in the last patient. Additionally, stent implantation into the cavo-atrial junction could be a matter of concern because of alteration of the sinus node. Therefore the banding was performed as near as possible to the cavopulmonary anastomoses, and the stents were placed as high as possible in the superior vena cava to prevent mechanical interference with the sinus node. Sinus node dysfunction was not observed in any of our patients during the follow up period of four to 14 months. Another matter of concern could be that an implanted endovascular stent does not allow growth of the cavo-atrial junction, in contrast to surgical techniques. However, the Palmaz stents used can be redilated to a diameter of $20 \mathrm{~mm}$. Although dilatation of these stents is recommended to a diameter of $16 \mathrm{~mm}$, expansion up to $20 \mathrm{~mm}$ is possible in our experience. We believe a cavopulmonary junction with a diameter of $20 \mathrm{~mm}$ should give adequate communication. We would not perform angioplasty or recommend surgery on a cavo-pulmonary junction with a diameter of 18 to $20 \mathrm{~mm}$ after total cavopulmonary connection or another Fontan-type procedure. Such a diameter is equal to that of an extracardiac conduit which is implanted surgically. ${ }^{18}$ Finally, tissue growth or thrombotic deposits within the covered wallstent observed in one patient could be a matter of concern (fig 2B); however, no pressure gradient within the stent was observed, and this tissue had regressed 12 months after the implantation (fig 2C). Despite this, we suggest that anticoagulation with dicoumarol is necessary after implantation of a covered wallstent to prevent thrombotic deposits within the covered wallstents.

Until more experience with this new approach is gained, and long term follow up data acquired, it cannot be decided which of the two techniques used for transcatheter Fontan completion is to be preferred: implanting a covered wallstent as an "intracardiac conduit" or restricting stent implantation to the cavo-atrial junction with subsequent occlusion of the multiperforated baffle with umbrellas. The use of a covered wallstent as intracardiac conduit offers the advantage of excluding the right atrium from the circulation, thereby protecting it from distension by an increased venous pressure, and hence reducing the incidence of late dysrhythmias. However, restricting stent implantation to the cavo-atrial junction with subsequent umbrella closure of the multiperforated baffle offers the advantage of leaving a residual leak in the baffle, converting the hemifontan circulation to a "fenestrated" Fontan circulation, with the option of occluding this residual fenestration later. Using this approach the interventional Fontan completion can be staged, allowing a smooth conversion to a univentricular repair according to the Fontan principle, potentially reducing morbidity and improving quality of life.

1 Bridges ND, Jonas RA, Mayer JE, Flanagan MF, Keane JF, Castaneda AR. Bidirectional cavopulmonary anastomosis as interim palliation for high risk Fontan candidates. Circulation 1990;82(suppl)IV:170-6.

2 Senzaki H, Isoda T, Ishizawa A, Hishi T. Reconsideration of the criteria for the Fontan operation. Influence of pulmonary artery size on postoperative hemodynamics

3 Bridges ND with subsequent transcatheter closure. Circulation 1990; with subsequen

4 Bridges ND, Mayer JE, Lock JE, Jonas RA, Hanley FL, Keane JF, et al. Effect of fenestration on outcome of the modified Fontan repair. Circulation 1992;86:1762-9.

5 Kirklin JK, Blackstone EH, Kirklin JW, Pacifico AD, Bargeron LM. The Fontan operation. Ventricular hyperBargeron LM. The Fontan operation. Ventricular hyper-
arophy, age and date of operation as risk factors. $\mathcal{F}$ Thorac Cardiovasc Surg 1986;92:1049-64. 
6 Mayer JE, Bridges ND, Lock JE, Hanley FL, Jonas RA, Castaneda AR. Factors associated with marked reduction ventricle. $\mathcal{F}$ Thorac Cardiovasc Surg 1992;103:444-52.

7 Jacobs ML, Norwood WI. Fontan operation: influence of modifications on morbidity and mortality. Ann Thorac Surg 1994;58:945-52.

8 Pridjian AK, Mendelsohn AM, Lupinetti FM, Beekman RH, Dick M, Serwer G, et al. Usefulness of the bidirectional Glenn procedure as staged reconstruction for the tional Glenn procedure as staged reconstruction for the
functional single ventricle. $A m \mathcal{F}$ Cardiol 1993;71:959-62.

9 Perry SB, Lock JE. Front loading of double umbrella devices, a new technique for umbrella delivery for closing
cardiovascular defects. Am 7 Cardiol 1992;70:917-20.

10 Jonas RA. Indications and timing for the bidirectional Glenn shunt versus the fenestrated Fontan circulation. $f$ Thorac Cardiovasc Surg 1994;108:522-4.

11 Mayer JE, Helgason H, Jonas RA, Lang P, Vargas FJ, Cook N, Castaneda AR. Extending the limits for modified Fontan procedures. F Thorac Cardiovasc Surg 1986;92: 1021-28

12 Cromme-Dijkhuis AH, Hess J, Hahlen K, Henkens K, Bink-Boelkens MT, Eygelaar AA, et al. Specific sequelae after Fontan operation at mid- and long-term follow-up. Arrhythmia, liver dysfunction, and coagulation disorders. f Thorac Cardiovasc Surg 1993;106:1126-32.
13 Chang AC, Hanley FL, Wernovsky G, Rosenfeld HM, Wessel HM, Jonas RA, et al. Early bidirectional cavopulmonary shunt in young infants. Postoperative course and early results. Circulation 1993;88:II149-58.

14 Mainwaring RD, Lamberti JJ, Moore JW, Billman GF, Nelson JC. Comparison of the hormonal response after bidirectional Glenn and Fontan procedures. Ann Thorac Surg 1994;57:59-61.

15 Gewillig MH, Lundstrom UR, Deanfield JE, Bull C, Franklin RC, Graham TP, et al. Impact of FontanFranklin RC, Graham TP, et al. Impact of Fontan-
operation on left ventricular size and contractility in trioperation on left ventricular size and contract
cuspid atresia. Circulation 1990;81:118-27.

16 Sluysmans T, Sanders SP, van der Velde M, Matitiau A, Parness IA, Spevac PJ, et al. Natural history and patterns Parness IA, Spevac PJ, et al. Natural history and patterns
of recovery of contractile function in a single left ventricle of recovery of contractile function in a single left ventric

17 Reddy VM, Liddicoat JR, Hanley FL. Primary bidirectional superior cavopulmonary shunt in infants between 1 and 4 months of age. Ann Thorac Surg 1995;59:1120-6.

18 Marcelletti C, Corno A, Giannico S, Marino B. Inferior vena cava-pulmonary artery extracardiac conduit: a new form of right heart bypass. $\mathcal{f}$ Thorac Cardiovasc Surg 1990;100:228-32.

19 Cecchin F, Johnsrude CL, Perry JC, Friedman RA. Effect of age and surgical technique on symptomatic arrythmias after the Fontan procedure. Am $\mathcal{F}$ Cardiol 1995;76:386-91. 